\title{
Research on Development Mode of Contemporary English Language and Literature in China from the Perspective of Local Culture
}

\author{
Qiaohong Wang \\ School Of Foreign Languages, Zhengzhou University Of Industrial Technology, \\ Henan, 451100 China
}

\begin{abstract}
In this paper, we conduct research on the development mode of the contemporary English language and literature in China from the perspective of local culture. Along with the development of the economic globalization, for people to further improve the English level requirements, not only requires people can speak fluent English, but also requires people to have profound primary level of knowledge of English culture, which makes the cultivation of the cross-cultural awareness more and more get the attention of people, and is an effective way of training in the cultivation of cross-cultural awareness in the teaching of English literature. Literature as the primary component of the English will help us to feel the language better. Our research combines the local culture to suggest the further developmental trend of English language and literature in China that is meaningful.
\end{abstract}

Keywords- Development Mode, English Language, Local Culture, China, Literature, Perspective.

\section{Introduction}

Study of Chinese American literature is immense, various research models, literary theory has come in handy, from literature research to cultural study, from the Chinese ideology and culture, the literary theory to the western philosophy, literature and art theory, Chinese American literature this piece of fertile soil for a variety of ancient and modern, Chinese and foreign new old literary research weapons training ground. Also appeared the phenomenon of multidisciplinary joint development, from foreign literature of Chinese American literature research in British and American literature, the overseas Chinese literature in Chinese modern and contemporary literature research, to comparative literature across civilizations, across different culture, language, interdisciplinary research Chinese American literature is the appreciation of each professional researchers that become the subject for the base.

From a certain extent, the better comprehensive language ability should be very close to a language including speaking, reading and writing of culture or cultural literacy that can be summarized as the listed aspects. (1) Language learning needs a large number of inputs might have the correct output, literary language is a reflection of the essence of language and linguistic diversity, involving the most elegant written language and the most popular colloquial, which can follow the language environment for language learning and imitating samples. (2) Through reading and analyzing the literature, taste different writers of different style, different language style as student can learn from the surface into the deeper level of language learning and improve the literature accomplishment and the aesthetic. (3) Language and culture are inseparable, the culture, so language is the language could not transcend culture and exist independently, language is bearing the rich cultural connotation, language learning and culture learning and culture learning and literary study is an effective and direct way [1-3].

The way people use fuzzy express the metaphor, the expression is literally impossible to express, as need to be connected between the body and the body, the association is a similar associations in the field of cognitive, due to the effect of the cognitive commonness of the people, 
when people face the same thing, will produce similar associations. Usually, the understanding of metaphor has two stages, one stage is a metaphor recognition, another stage is deduced the implication of the metaphor. In metaphor identification stage, the main conflict is based on the literal meaning and context, from the principle, and this conflict is inevitable, only more within the larger context of the law to eliminate the conflict. It is the main part of the linguistic theory of linguistics, is the theoretical foundation and core of linguistics, it includes the study of specific individual language and the comprehensive study of the many languages as the applied linguistics refers to the use of linguistics theories related to language problems. In theory, individual linguistic study, the more the more conducive to the development of the theory of the general linguistics, because in individual linguistic research is the theory of general linguistics gradually established and developed on the basis of the integrity of the general linguistics theory depends on the study of the specific language and the research achievements. Therefore, in this paper, we conduct research on development mode of contemporary English language and literature in China from the perspective of local culture that will be illustrated in the later sections.

\section{WHAT IS LITERATURE?}

It is a form of human expression,

communicated by means of words in a

text having aesthetic value.

It is the use of language and creativity to

evolke a personal response in the reader.

It is a world of fantasy, horror, feelings,

ideas, criticism... put into words.

Figure 1. The Definitions and Features of the

English Language

\section{Our Proposed Perspective}

The Characteristics of Local Culture. Language and culture are the two complement each other, depend on each other individuals. In the process of translation, the surface is the one language into another language, is actually two kinds of culture communication. Because words only in the role of cultural background. Language is rooted in a specific culture, and culture is a language structure as its center, language and culture are inseparable. Language is the main vehicle for cultural and the basis, reflects the core particular culture of the society in which they operate. Culture constitutes the core connotation of language, the language of the external image and internal integration plays a key role, to understand through analyzing the deeply hidden cultural representation language, social structure, political system, customs and other cultural differences. At the same time, the cultural constraints on verbal communication, in the process of communication will inevitably produce the cultural conflict and collision with the formation of cultural differences [4-5].

The functionality of the local culture can be generally organized as follows. (1) Helps to cultivate the students' intercultural communicative competence. Intercultural communication not only limited to the understanding of the communication object, but also should be Shared and cultural impact on the communication object. China's local culture and profound has a long history, with typical Chinese cultural features. (2) Help to improve student consciousness of national culture. Strengthen the import local culture, not only help students use English express their own history, social and cultural values, economic life and cultural education, but also necessary for the college students to keep their cultural identity and personality status. (3) Help students better understand the foreign culture and improve the cognition of culture. Only perceiving alien culture can have a more profound understanding of their native culture, only know the native culture can we know foreign culture better, and only the native culture and the target language culture in-depth comparison and discussion, in 
order to deepen the students to understanding the native culture that the aim will be achieved.

China's traditional culture has a long history that has created five thousand years of the Chinese civilization, it is not better than any kind of the civilization. As a scholar of the younger generation, should be more shouldering the historical responsibility of inheritance and carry forward the Chinese culture, promote national consciousness, the native culture to absorb and the essence of which is to ascend, so as to promote China's outstanding traditional culture to the world, the rich world cultural treasure house. To master the essence of the national culture, draw lessons from and absorbing foreign culture quality ingredients, with systematically comprehend the similarities and differences between Chinese and western culture, cultivate and form the sensitivity of the culture and the discrimination ability of the rational, update language cultural concept, inspire patriotic feelings to make our country really has the national pride and sense of responsibility to the younger generation [6].

The English Language and Linguistics. In today's language vocabulary in one direction, with the development of the teaching is to materialize learned vocabulary and imagery.
Work system of the metaphor is the mapping of the source domain to target domain that is from the familiar and easy to understand the specific source domain, is mapped to an unfamiliar or difficult to understand the more abstract target domain, in order to achieve to understand the purpose of the target domain. So, an important role of metaphor is to make the abstract concept of very strong, into the concept of iconicity is stronger. In this sense, in the English vocabulary teaching, the metaphor is to make some abstract concept into a visual vocabulary important cognitive tool of concept.

In the past we have more study from the grammar of the common level, such as the grammar and corresponding semantic grammar problems, this is what we call traditional grammar analysis about the phenomenon of the verbs. The other one is a human type. Nominalization phenomenon is mainly a conversion process, this process by putting a short phrase sentence is converted to the corresponding meaning, form of the verbs according to process and said the attribute adjectives converted to has the characteristics of noun phrases. In the figure two, we show the related keywords.

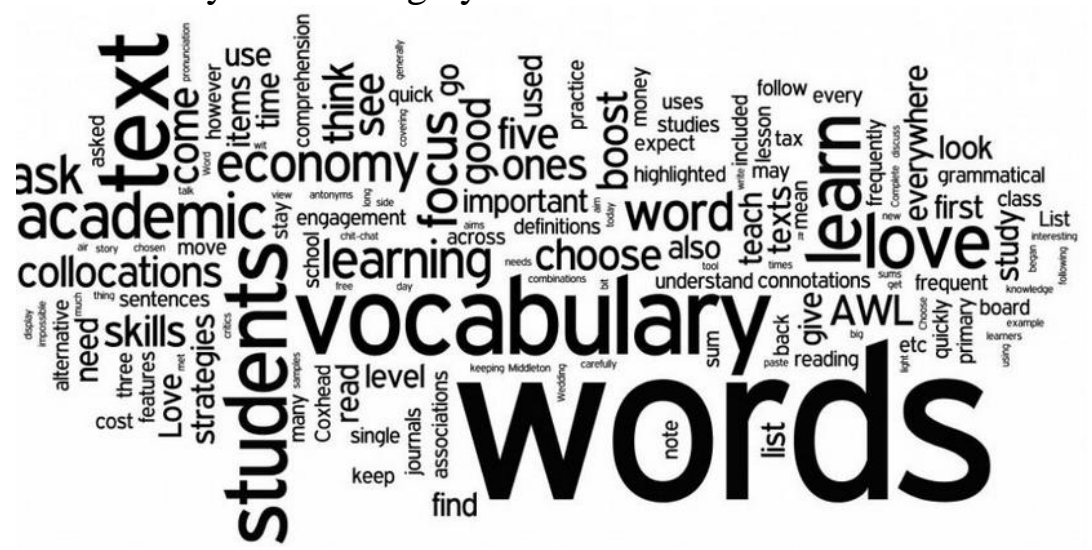

Figure 2. The Key Definitions of the English Language and Linguistics

According to the cognitive linguistics, the semantic category meanings of members with different position, they have a center of meanings, typical meanings and edge points, namely the core meaning, on the basis of a certain semantic prototype or further extension or radiation out other meanings, thus forming the meaning of the radiation field, grew with a higher level of abstraction of the meaning. 
In cognitive linguistics, basic metaphor is regarded as the abstract things, understanding and the expression of the powerful tools that is ubiquitous and is an important cognitive model. A metaphor is using another kind of concept a concept to express this would require the similarities between the two concepts. About the classification of metaphor, the scholars according to the original domain different conceptual metaphors can be divided into the three types: structural metaphor, orientation and entity metaphor. In the theory of cognitive linguistics, cognitive metaphor is a kind of important cognitive style. It is not only a rhetorical technique, or the people in the process of the life constantly cognitive world a cognitive approach. From one thing to understand another, from one experience to understand another, in the metaphor cognitive context is indispensable, ignore the context, so the production of the metaphor is impossible that also have no function [7-8].

Therefore, after understand the relationship between context and metaphor, it will be a very good to the similarity of the both basic theory is introduced into English vocabulary teaching. For the basic characteristics of the meaning we usually adopt the way of the systemic functional linguistics in this paper, the cognitive. Systemic functional linguistics this paper refers to by a variety of the ways and concepts are the existing knowledge system of a network, have administrative levels feeling and then throughout the network, the system structure of the form. Systemic functional linguistics in this paper, the process and the structure of the relevant experience is a process of linguistics, is a basic mode of analogy, on the brain, one of the most representative analogy model occurs in all sensory area, become to illustrate the feedback of systemic functional linguistics.

The English Literature. As the language of the theory research gradually thorough, the college English teaching in cultivating the students' English and the American literature consciousness and ability will become the focus of a new round of reform of basic university English. Literature as an important branch of humanities, literature accomplishment as an important one of the quality of talents, in higher education, should become a big, British and American literature teaching should also be incorporated into college English teaching system, should be in the college English teaching to cultivate students English and American literature accomplishment.

Literature is bearing the weight of the culture of a country, with the spirit and soul of a nation, reflecting the cultural heritage of a country, customs and habits, spirit and so on. Similarly, English literature is bearing the culture and custom of English-speaking countries, local conditions and the customs. Regularity in English literature teaching innovation should establish teacher guide students to understand the richness of humanities connotation has made under the premise of. Humanities have rich connotation is very broad, and also have the obvious role to student's life and influence.

Literature can be infinite interpretation and everyone for personal different life experiences to the work of the resonance, and the contents and basic forms of the literature is extremely rich, profound connotation of inexhaustible. This is for the reader's thinking ability provides unlimited space for the development. People read literature is not passive, students are not in accordance with a fixed pattern, regulations such as the grammatical rules of the language, and so on to interpret any kind of literary phenomenon, but according to the character of independent way of thinking for creative thinking, give full play to your ability to discover problems, analyze and solve problems, in order to achieve their artistic conception. Literary language is a reflection of the essence of general language and linguistic diversity, involving the most elegant written language and the most popular colloquial, which can follow the language environment for the language learning and imitating samples. 
Reading literary works, students can appreciate the essence of the language arts, to reap the language background, unique language training, at the same time, the different age of the author's work can provide students with the structure of the language used to the various examples that make the students to improve the structure of their own language, improve the quality of the language.

The Chinese Language Literature. Modern Chinese literature is in opposition to classical Chinese, is the important content of literary revolution, the May 4th movement, as a basic result of its special language background early revolution, the language of the emergence and development of the new literature form has the decisive significance. New literature style form as a product of this basic language revolution, to a great extent, takes the positive and negative consequences of linguistic revolution. Examine the objective of the revolutionary language and literary style of the complicated relationship between aesthetic appeals can deepen in modern literary style and the understanding of the basic characteristics and evolution.

People care about literature, to the extent is a concern for language, for language and what is the meaning of the relationship between each other care, concern for the relationships between language speaking and how to say. Literature is the imaginative work. Imagination is formed in the special context. A language from other contexts, detachment from other purposes, is itself a context that can promote or causes the recipient's unique thinking, have imagination, can be interpreted as literature.

For general national culture corresponding cultural globalization and localization are proposed and national culture and the convergence of globalization to people of all nationalities, and localization to the divergence of national culture. In the modern times until the current reality, the convergence and divergence crisscross tangles as literary theory localization problem of complex and difficult. For core literary theory, the local reality, the first is the actual language. Language is an important factor of the national features, especially constitute an important factor of primary national literary features, so the aboriginality of literary theory, and it is closely related to the understanding of local language features.

\section{Conclusion}

In this paper, we conduct research on the development mode of contemporary English language and literature in China from the perspective of local culture. In English literature teaching, teachers need to be on the basis of importance to improve the students' English literacy will cultivate the students' English quality and culture, as one of the important starting point. English literature in the process, reading is guides the student to make a cognitive, to the world of information collecting, the aesthetic information acquisition and effective method to develop students' thinking, so in the English literature teaching, teachers should attach importance to cultivate students' English reading ability, especially in the reading of English literature to make students learn dialectical and critical methods. Therefore, we combine the local culture to propose the novel perspective of contemporary English language and the literature that is beneficial for the further development.

\section{Reference}

[1] Gross, Michael J., Hailian Gao, and Songshan Sam Huang. "China hotel research: A systematic review of the English language academic literature." Tourism Management Perspectives 6 (2013): 68-78.

[2] DiCerbo, Patricia A., et al. "A review of the literature on teaching academic English to English language learners." Review of Educational Research 84.3 (2014): 446-482. 
[3] Hesping, Frank, and Holger Schiele. "Towards a framework for strategy in purchasing: German and English language literature." Supply Management Research. Springer Fachmedien Wiesbaden, 2013. 57-86.

[4] Nalysnyk, Luba, et al. "Incidence and prevalence of idiopathic pulmonary fibrosis: review of the literature." European Respiratory Review 21.126 (2012): 355-361.

[5] Kennedy, Victor. "Critical, Cultural and Multimodal Approaches to Using Song as Literature in Language Learning." Libri \& Liberi 3.2 (2014): 295-310.

[6] Bolton, Kingsley, and Maria Kuteeva. "English as an academic language at a
Swedish university: parallel language use and the "threat'of English." Journal of Multilingual and Multicultural Development 33.5 (2012): 429-447.

[7] Qi, Xingshun, et al. "Scientific Publications on Portal Vein rombosis and Budd-Chiari Syndrome: a Global Survey of the Literature." J Gastrointestin Liver Dis 23.1 (2014): 65-71.

[8] Musa, Normazidah Che, Yew Lie Koo, and Hazita Azman. "Exploring English language learning and teaching in Malaysia." GEMA: Online Journal of Language Studies 12.1 (2012): 35-51. 